\title{
OPTIMIZATION OF URBAN MINI-BUS STOP SPACING: A CASE STUDY OF SHANGHAI (CHINA)
}

\author{
Zhenjun Zhu, Xiucheng Guo, Hongsheng Chen, Jun Zeng, Jiangling Wu
}

Preliminary communication

In recent years, the mini-bus service has gained a rapid development, while the reasonable stop spacing is significant to improve residents' travel efficiency. In order to locate the mini-bus stops practically, this paper firstly proposes a mathematical model based on Voronoi Diagrams to minimize residents' total travel time. Improved Wilson-Han-Powell Sequential Quadratic Programming (SQP) technique is employed to solve the model. Based on Geographic Information Systems (GIS), the Cartesian coordinate system is used to calculate the walking distance between mini-bus stops and origins or destinations, which cannot be directly measured. Secondly, based on the actual situation, this paper proposes modification methods for adjusting mini-bus stops. The validity and usefulness of the methodology is tested through applying it to a real case in Shanghai (China). The calculation results suggest that the model deals well with the mini-bus stop spacing problem.

Keywords: mini-bus service; modification methods; optimization model; Sequential Quadratic Programming; stop spacing; Voronoi Diagrams

Optimizacija razmaka između stajališta gradskog mini-autobusa: studija slučaja Šangaj (Kina)

Prethodno priopćenje

U posljednjih se nekoliko godina služba mini-autobusa brzo razvija, a odgovarajući razmak između stajališta značajno poboljšava učinkovitost putovanja stanovnika. Kako bi mini-bus stajališta bila praktično locirana, u ovom se radu najprije predlaže matematički model temeljen na Voronoi dijagramima u svrhu smanjenja ukupnog vremena putovanja putnika. Za rješenje tog modela primijenjena je poboljšana tehnika Wilson-Han-Powell sekvencionalno kvadratno programiranje (SQP). Na temelju geografskih informacijskih sustava (GIS) korišten je Kartezijanski koordinatni sustav za izračunavanje pješačke udaljenosti između mini-bus stanica i početnih ili odredišta, koja se ne mogu izravno izmjeriti. Drugo, u skladu sa stvarnim stanjem, u radu se predlažu metode modifikacije za podešavanje stajališta mini-autobusa. Valjanost i korisnost metodologije ispitana je njenom primjenom na stvarnom slučaju u Šangaju (Kina). Rezultati proračuna pokazuje da se modelom dobro rješava problem određivanja razmaka između stajališta mini autobusa.

Ključne riječi: metode modifikacije; model optimizacije; sekvencionalno kvadratno programiranje; služba mini-autobusa; razmak između stajališta; Voronoi dijagrami

\section{Introduction}

Mini-bus lines are initially opened by real estate developers and property management companies for providing new check-living residents with convenient travel services. Then, they gradually evolve into feeder bus lines to improve urban passenger transportation system [1]. Mini-bus is also called a pocket bus, community bus, shuttle bus, circulation bus, feeder bus, last-kilometre bus and so on. However, there is still no specific or unified definition for a mini-bus. In practice, some of shorter or smaller buses are also called a minibus, which is one-sided [2]. In this paper, the term minibus refers to small public transport vehicles approximately $7 \mathrm{~m}$ in size that flexibly shuttle in urban branch roads or community roads along predetermined lines and stops, provide the short-distance travel service as a feeder for rail transit stations, transportation hubs and adapter residential areas, schools, community service centres, hospitals, shopping malls and other passenger distribution points.

Nowadays, one of the main concerns regarding urban planning is public transportation. As an important part of urban public transportation operation modes, mini-bus lines can be arranged to match rail, bus rapid transit stations and passenger distribution sites. Mini-buses run on small streets (refer to the narrow streets), penetrate deeply into various residential areas and other functional areas and fill the service blank where mass transit and regular bus left. Also, Mini-bus services pay attention to the travel quality of elderly and vulnerable groups, improve travel convenience and travel accessibility of the elderly and provide an effective regional distribution service for rail transit stations. Therefore, Mini-bus effectively extends the rail transit, bus rapid transit service and solves the problem of short-distance travel and interchange.

Mini-bus lines should be aligned with passengers' wishes, while the impact of the selected lines and stop point micro-location on other subsystems (conventional bus, tram, rail transit, et al.) should not be ignored. The number of mini-bus stops and the distance between minibus stops are important indexes to evaluate the public transport system $[3,4]$. They can affect factors such as passengers' convenience, vehicles' operation speed, frequency, fleet size and so on $[5,6]$. Therefore, optimization of the mini-bus stop spacing can effectively improve the performance of public transportation system.

\section{Literature review}

A large number of studies have been conducted on stop spacing optimization with respect to conventional bus. Generally, an expert system is usually applied to locate bus stops appropriately based on rich experience. For example, Ammons [7] analysed various patterns of bus stop spacing around the world and found that the average spacing is from $200 \mathrm{~m}$ to $600 \mathrm{~m}$ in urban areas. Reilly [8] noticed that European traffic departments have different standards to determine bus stop spacing, the spacing varied from 330 to $550 \mathrm{~m}$, in opposition to United States standards where the spacing is from 160 to $250 \mathrm{~m}$. Geographic Information Systems (GIS) analysis is another method used by Sankar et al. [9] and El-Shair 
[10]. El-Shair [10] analysed a buffer zone of $300 \mathrm{~m}$ from all bus stops, which could cover $80 \%$ or more of residential or commercial land-use to obtain the optimal bus stop spacing. These studies do not follow a scientific procedure to determine the bus stop spacing. The third method for locating bus stops is the mathematical optimization model. For example, Wirasinghe and Ghoneim [11] discussed optimization problems of average bus stop spacing and established a model based on bus operation costs and passenger travel expenses. Kuah and Perl [12] proposed a model for the distance between stops based on the square-grid urban road network, which jointly optimized route spacing, headway and stop spacing. Furth and Rahbee [13] established a model on the basis of passengers' arrival discrete model and dynamic principles and calculated the optimal bus stops pacing was $400 \mathrm{~m}$ of a bus line in Boston. Saka [14] proposed optimization model of average bus stop spacing under constraints of operation costs. Chien and Qin [4] optimized the number and locations of stops on a realistic route network, in which the accessibility of bus service was improved. Alterkawi [3] used the field-collected data from the city of Riyadh, Kingdom of Saudi Arabia and simulated the optimal bus stop spacing. The results of the analysis performed on old airport road showed that amelioration of the problem of "weaving" can be accomplished without a significant reduction in service to passengers. Ibeas et al. [15] proposed a mathematical bilevel optimization model to get the average bus stop spacing with the objective of minimizing the social cost of the overall transport system. The model was applied to the medium-sized city of Santander, which optimized the existing system and improved the public transport service. Delmelle et al. [16] proposed a spatial interaction coverage model by considering both the impact of walking distance from an individual residential location to a stop and the transit facility attractiveness. The model was applied to route 9 in the city of Charlotte, North Carolina, which provided an alternate approach to model public transit efficiency and redundancy. Zhao and Chien [17] explored the potential cost reduction that is achieved by considering the relationship among variance of interarrival time, stop spacing and headway. In a numerical example, the developed model is applied to planning a feeder bus route in Newark, New Jersey. Tica et al. [18] emphasized that the micro location of the bus stop should be determined in accordance with the wishes of passengers' lines (matrix origin-destination), in order to minimize the length and walking time to the nearest stop, and therefore the total travel time ("door to door"). By selecting micro location of the stop point the impact of the public transport to remaining dynamic traffic should be minimize and vice versa (here is primarily to position stop points in relation to the intersection). This certainly affects the size of the stop distance.

Above studies attempted to solve the optimal average bus stop spacing, while the results are difficult to be directly applied to locate bus stops accurately on a line. What's more, existing studies mainly focus on conventional bus, while mini-bus is less concerned. Generally speaking, there are three different optimization objectives. For travellers, they expect minimum total travel time, operators always expect minimum costs and maximum income when meeting certain level of service, governments expect to maximize social and economic benefits [19]. However, public transport companies in China are state-operated and have obvious nature of public goods. The chief goal of their decision making is to meet the travel demand of most travellers.

Mini-bus lines mainly serve for "the last kilometre" of residents' travel. Existing studies have found that the primary function of mini-bus is to serve as a feeder for urban rail transit, which could obtain better social and economic benefits [20]. Therefore, considering China's current conditions, this paper takes a mini-bus as a feeder for rail transit stations as a research subject, through defining the service area of mini-bus. We propose a mathematical model based on Voronoi Diagrams to minimize travellers' total travel time, which is simple to get the optimal mini-bus stop spacing. Finally, Shanghai is taken as a case study to verify the proposed methodology.

\section{Methodology 3.1 Optimization objectives}

To ensure a high level of service for public transit users, walking distances to stops should be as short as possible. Farwell and Marx [21], Schöbel [22], Groß [23] stated that people consider walk time to be much less convenient than in-vehicle travel time and proposed a maximum walk distance of 400 metres to a transit stop. Reducing total travel time to stops will make the mini-bus service more attractive. However, different passengers have different requirements for mini-bus stop spacing. For in-vehicle passengers, they expect to reach destinations as quickly as possible. For passengers who get on or off the mini-bus, they expect the walk time is as short as possible Therefore, the objective of the optimization model is to minimize the total travel time.

\subsection{Optimization model 3.2.1 Analysis of travel process}

For passengers who travel by mini-bus, their travel process includes four steps: walk to the nearest mini-bus stop, wait for a mini-bus, travel by mini-bus, get off and walk to their destinations. Therefore, passengers' total travel time can be calculated as follows.

$T=T_{1}+T_{2}+T_{3}+T_{4}$

where $T$ is the total travel time. $T_{1}$ is the walk time to the nearest mini-bus stop. $T_{2}$ is the waiting time at mini-bus stops. $T_{3}$ is in-vehicle travel time. $T_{4}$ is the walking time to destinations.

$T_{1}$ and $T_{4}$ are related to the land use, surrounding road network density and bus stop location. Regarding the distance between mini-bus stops and destinations that cannot be directly measured, additionally existing studies have studied the service area of mini-bus in a rectangular area $[24,25]$. Therefore, GIS is adopted to establish the Cartesian coordinate system.

The concept of Voronoi Diagram is simple. Given a finite set of distinct, isolated points in a continuous space, all locations in that space can be associated with the 
closest member of the point set with respect to Euclidean distance. The result is a tessellation of the plane into a set of regions, where each region is related to only one of the points of the original set. In the actual situation, mini-bus demand is isolated in a set of distinct. Due to the population density of each district being different, minibus demand varies, assuming that each district has different weights. Therefore, an additively weighted Voronoi Diagram could be characterized by the weighted distance, as shown in Eq. (2) and Fig. 1.

$$
d_{e}\left(p, p_{i}\right)=\left\|x-x_{i}\right\|-w_{i},
$$

where $d_{e}$ is the Euclidean distance. $w_{i}$ is the weight associated with each point $i$.

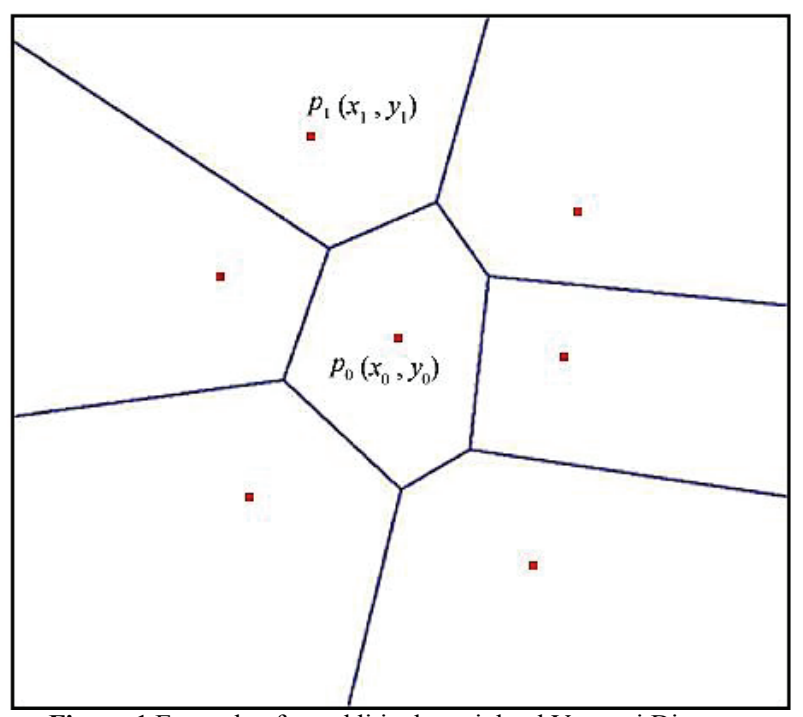

Figure 1 Example of an additively weighted Voronoi Diagram

The population density $\varphi(x, y)$ can be defined in relation with the variables $x$ and $y$. Service area of a minibus line is called $S$, mini-bus stops are represented as $s_{i}$, where $i \in I$. The distance $d_{i}$ is the mini-bus stop spacing between stop $i-1$ and $i$, as is shown in Fig. 2.

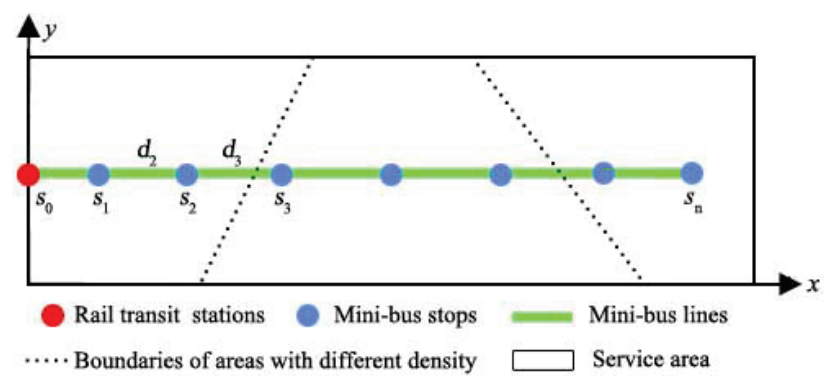

Figure 2 The mini-bus line in coordinate system

Thus, passengers' origins or destinations and mini-bus stops can be respectively expressed as $p\left(x_{0}, y_{0}\right), s_{1}\left(x_{1}, y_{1}\right)$, being $p, s_{1} \in S$.

$T_{1}$ and $T_{4}$ represent the same path from origins to mini-bus stops and vice versa. According to the survey in China, for most of passengers who travel by mini-bus, we found that the walk time to the nearest mini-bus stop and the walking time to destinations are approximately the same. Therefore, in order to simplify the optimization model, we assume that $T_{1}=T_{4}$, which can be calculated as follows.

$$
T_{1}=T_{4}=\frac{k \times \sqrt{\left(x_{1}-x_{0}\right)^{2}+\left(y_{1}-y_{0}\right)^{2}}}{v_{w}}=\frac{\left\|p-s_{1}\right\|}{v_{w}},
$$

where $k$ is a correction factor to approximate the Euclidean distance to a walk distance. In this paper, the value of $k$ can be assigned 1,3 [26]. $v_{\mathrm{w}}$ is the walking speed of passengers.

Assuming that the average waiting time at mini-bus stops belong to the uniform distribution of $\mathrm{X} \sim \mathrm{U}\left(0, t_{1}\right), T_{2}$ can be calculated as follows.

$$
T_{2}=0,5 t_{1}=\frac{q_{r} \times \beta \times 30}{q_{p}}
$$

where $t_{1}$ is the headway. $q_{r}$ is the rated capacity. $\beta$ is the rate of full load. $q_{p}$ is the peak link volume in a direction.

$T_{3}$ contains travel time in average travel speed $T_{31}$, acceleration and deceleration time $T_{32}$, passenger boarding and disembarkation time $T_{33}$, time delay due to traffic control $T_{34} . T_{32}$ is deeply affected by the number of passengers getting on or off [27], $T_{34}$ is also affected by random traffic, in order to concentrate on the time spent at mini-bus stops, the values of $T_{32}$ and $T_{34}$ are regarded as constant $u$. Therefore, in-vehicle travel time $T_{3}$, namely the travel time from stop $i$ to the terminal can be calculated as follows.

$$
T_{3}=T_{31}+T_{32}+T_{33}+T_{34}=\frac{d_{i}}{v_{\mathrm{veh}}}+i \times\left(\frac{2(a+b) v_{\mathrm{veh}}}{\mathrm{ab}}+u\right)
$$

where $d_{i}$ is the distance from mini-bus stop $i$ to the terminal. $v_{\mathrm{veh}}$ is the average travel speed of the mini-bus on the route. $a$ and $b$ are respectively normal acceleration and deceleration rate of mini-bus. The passenger's total travel time is calculated as follows.

$$
T=2 \times \frac{\left\|p-s_{i}\right\|}{v_{\mathrm{veh}}}+\frac{q_{r} \times \beta \times 30}{q_{p}}+\frac{d_{i}}{v_{\mathrm{veh}}}+i \times\left(\frac{2(a+b) v_{\mathrm{veh}}}{\mathrm{ab}}+u\right)
$$

\subsubsection{Constraints}

In the actual situation, the optimal mini-bus stop spacing $d_{\text {opt }}$ has upper and lower bound constraints. The minimum spacing $d_{\min }$ should be longer than the distance when mini-bus accelerates to normal speed and decelerates to zero. The maximum spacing $d_{\max }$ should be shorter than passengers' maximum tolerable walking distance. The domain of attraction of mini-bus stops is closely related to the land use, road network density, etc. So, there is a conversion factor of $\mu$ between the distanceto-stop and service radius. Assuming that the service radius of the mini-bus stop $r$ is a circular area, $r$ can be calculated. 


$$
\begin{aligned}
& d_{\text {min }} \leq d_{\mathrm{opt}} \leq d_{\max } \\
& d_{\min }=\frac{v_{\mathrm{veh}}^{2}(a+b)}{2 a b} \\
& d_{\min }=2 r=2 \mu \sum_{i=1}^{m} v_{i} t_{i} f_{i},
\end{aligned}
$$

where $r$ is the service radius of the mini-bus stop. $\mu$ is the conversion factor. $v_{i}$ is the travel speed of the travel mode $i . t_{i}$ is the maximum tolerable time when passengers use the travel mode $i$. $m$ is the number of travel modes, here it refers to walking and bicycle modes. $f_{i}$ is the travel proportion of the travel mode $i$.

Passengers who travel by mini-bus have maximum tolerable walking time, which can be investigated through questionnaires.

$$
0<T_{1}=T_{4} \leq T_{\max } .
$$

\subsubsection{Optimization function}

Assuming that each passenger will go to mini-bus stops so as to minimize his total travel time, every minibus stop has its domain of attraction, which can be defined as follows.

$$
R_{\mathrm{i}}=\left\{\begin{array}{l}
2 \times \frac{k\left\|p-s_{i}\right\|}{v_{\mathrm{veh}}}+\frac{q_{r} \times \beta \times 30}{q_{p}}+\frac{d_{i}}{v_{\mathrm{veh}}}+ \\
i \times\left(\frac{2(a+b) v_{\mathrm{veh}}}{a b}+u\right) \leq 2 \times \frac{k\left\|p-s_{j}\right\|}{v_{\mathrm{veh}}}+ \\
\frac{q_{r} \times \beta \times 30}{q_{p}}+\frac{d_{j}}{v_{\mathrm{veh}}}+j \times\left(\frac{2(a+b) v_{\mathrm{veh}}}{a b}+u\right) \\
i \neq j ; i, j \in I_{n}
\end{array}\right\} .
$$

The domain of mini-bus stops has the characteristic of an additively weighted Voronoi Diagram area [28]. Therefore, the total travel time of all passengers in the studied area can be calculated as follows.

$T=\sum_{i=1}^{n} \int_{R_{i}}\left\{\begin{array}{l}2 \times \frac{k\left\|p-s_{i}\right\|}{v_{\mathrm{veh}}}+\frac{q_{r} \times \beta \times 30}{q_{p}}+ \\ \frac{d_{i}}{v_{\mathrm{veh}}}+i \times\left(\frac{2(a+b) v_{\mathrm{veh}}}{a b}+u\right)\end{array}\right\} \varphi(x, y) \mathrm{d} s$

Therefore, the optimization function is obtained as follows.

$\min T=\sum_{i=1}^{n} \int_{R_{i}}\left\{\begin{array}{c}2 \times \frac{k\left\|p-s_{i}\right\|}{v_{\mathrm{veh}}}+\frac{q_{r} \times \beta \times 30}{q_{p}}+ \\ \frac{d_{i}}{v_{\mathrm{veh}}}+i \times\left(\frac{2(a+b) v_{\mathrm{veh}}}{a b}+u\right)\end{array}\right\} \varphi(x, y) \mathrm{d} s$

subject to

$$
\frac{v_{\mathrm{veh}}^{2}(a+b)}{2 a b} \leq d_{\text {opt }} \leq 2 \mu \sum_{i=1}^{n} v_{i} t_{i} f_{i}, 0<\frac{k\left\|p-s_{i}\right\|}{v_{\mathrm{veh}}} \leq T_{\max }
$$

\subsubsection{Solution algorithms}

The optimization function is non-linear and constrained to extreme value problem. A large number of studies have been conducted on algorithms with respect to Voronoi Diagrams, while due to nonlinear characteristics, these problems are generally difficult to be solved and application software is fewer. The Wilson-Han-Powell Sequential Quadratic Programming SQP technique has proved highly effective for solving constrained optimization problems with smooth nonlinear functions in the objective and constraints [29]. Considering properties of global convergence and stability, the modified SQP technique is employed to calculate this problem $[30 \div 32]$.

In this class of algorithms, the constrained optimization problem is replaced by an unconstrained non-differentiable optimization problem. The algorithm determines a search direction by first solving a linear program and using the information gained thereby to define a quadratic approximation, with a guaranteed solution, to the original problem. The solution of the quadratic problem is the desired search direction. The algorithm incorporates a new method for choosing the penalty parameter. To obtain a super-linear rate of convergence for the algorithm, an arc search vector and a new updating scheme were employed. MATLAB software 7.0 is used to program the solution algorithms, and the optimization model can be solved.

\subsection{Modified methods for mini-bus stop spacing}

The optimal mini-bus stop spacing can be calculated by the above optimization model, while it should be modified to apply in a real case. Existing studies and practical engineering projects have proved that bus stops should have reasonable distance constraints between intersections, buildings and community entrances [4, 33]. The optimal mini-bus stop spacing is obtained by a mathematical model using continuous variables, which does not meet actual traffic conditions between stops, especially in urban areas [13]. Therefore, the method of average mini-bus stop spacing could result in stops locating at intersections and other improper positions. Therefore, in order to calculate the practical mini-bus stop spacing, actual traffic factors should be taken into account. Generally speaking, the optimal mini-bus stop spacing should be modified in the following aspects.

a) Intersections. If the optimal mini-bus stop is located at intersections, we should modify the spacing to dispose it at upstream or downstream of the intersection by referring to conventional bus stop location design. However, mini-buses mainly shuttle in urban branches or community roads, where conventional bus lines are fewer and traffic flow is relatively less. Thus, in complying with stop design principles, mini-bus stops can dispose at the reasonable location of intersections to promote passengers' convenience.

b) Road traffic conditions. The road width of urban branches or community roads is narrow, symmetric minibus stops on uplink and downlink lines should be staggered certain distances to minimize the traffic influence. 
c) Large traffic attraction points. The surrounding traffic is so complex, the mini-bus stops should not be located at the main entrance of commercial buildings, and should be staggered certain distances of $30 \div 50 \mathrm{~m}$ to ensure the evacuation of vehicles and pedestrians timely.

d) Economic feasibility. In the actual situation, the attribute of land use along the mini-bus line is not consistent, the value of land use surrounding the mini-bus stop is also different. Therefore, the construction cost of each mini-bus stop is not the same. Once the construction cost of a mini-bus stop is too high, which indicates that it is not an economic feasibility, we should deviate the calculated optimal mini-bus stop from a certain distance.

There are also other factors that affect the modification of optimal mini-bus stop spacing, such as policies, operation organization and so on. However, under any condition, the location of mini-bus stops must be determined based on passengers' convenience and safety.

\section{Case study \\ 4.1 Calculation and verification for the stop spacing}

The validity and usefulness of the methodology proposed in this paper has been tested through applying it to a real case. The area used for the application is in Shanghai, China with 200000 inhabitants and well established urban transport services, located in Changning district, the west of Shanghai. Since the operation of rail transit line 2, a large demand of short-distance travel exists at the rail transit station of Songhong. The Mini-bus line 1205 is opened to meet these demands, as shown in Fig. 3 and Tab. 1.

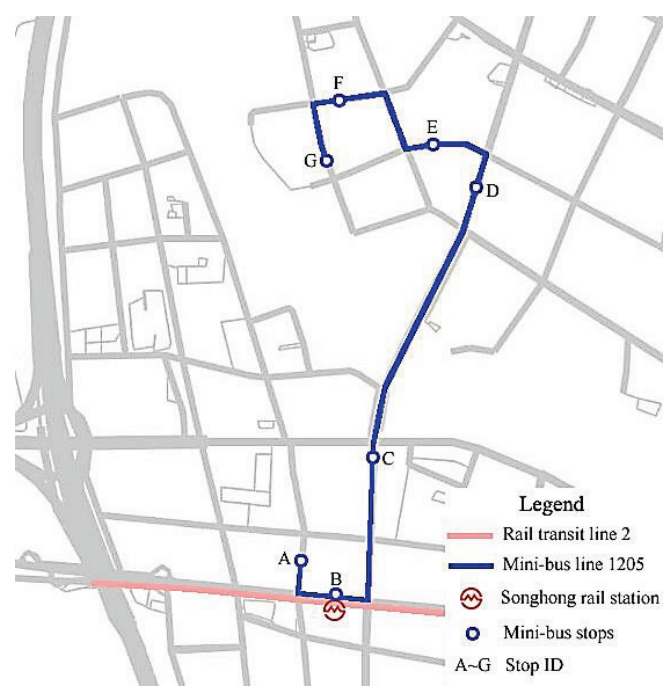

Figure 3 The status quo of mini-bus lines feeder for rail transit lines

Table 1 The basic information of mini-bus line 1205

\begin{tabular}{|c|c|c|c|}
\hline Stop ID & $\begin{array}{c}\text { Stop spacing } \\
(\mathrm{m})\end{array}$ & $\begin{array}{c}\text { Total length } \\
(\mathrm{km})\end{array}$ & $\begin{array}{c}\text { Average stop } \\
\text { spacing }(\mathrm{m})\end{array}$ \\
\hline A-B & 322 & & \\
\hline B-C & 622 & & \\
\hline C-D & 1148 & \multirow{2}{*}{3,3} & 5 \\
\cline { 1 - 2 } D-E & 370 & & \\
\hline E-F & 513 & & \\
\hline F-G & 325 & & \\
\hline
\end{tabular}

From the data above, we see that the average stop spacing of mini-bus line 1205 is relatively larger, which is not incompatible with its function of short-distance travel service. Therefore, the stop spacing of mini-bus line 1205 should be optimized. Based on the survey data, corresponding parameters are calibrated as follows: $a=$ $1,0 \mathrm{~m}^{2} / \mathrm{s}, b=-1,2 \mathrm{~m}^{2} / \mathrm{s}, v_{\mathrm{veh}}=1,2 \mathrm{~m} / \mathrm{s}, q_{r}=20$ people $/ \mathrm{veh}$, $q_{p}=1036$ people $/ \mathrm{h}, k=1,3, \beta=63 \%$.

The data used is from questionnaires and the fourth traffic survey report of Shanghai. The optimization model and solution algorithms are used to find the number of mini-bus stops from $n=6$ to $n=30$. The solutions show that the minimum total time is obtained in $n=11$, as shown in Fig. 4. Therefore, the average stop spacing is $330 \mathrm{~m}$.

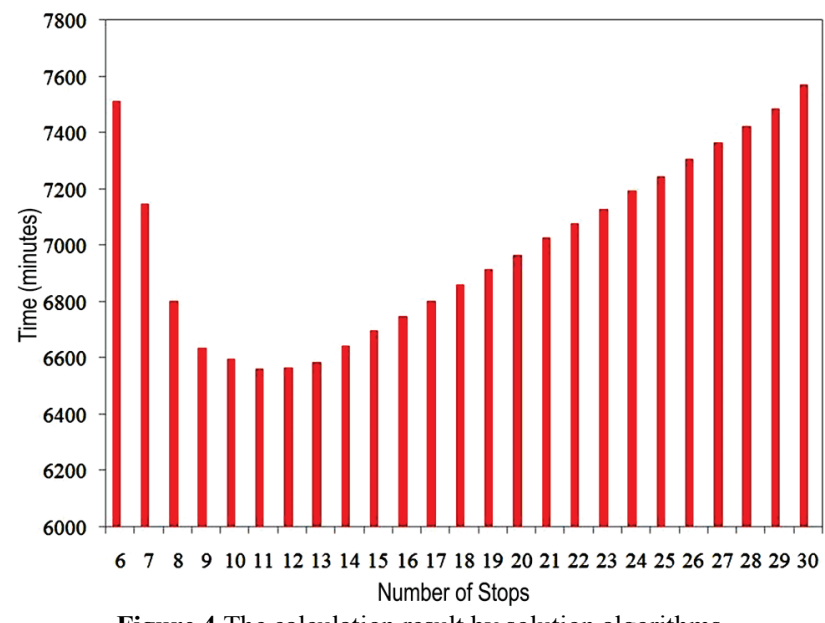

Figure 4 The calculation result by solution algorithms

To test the validity of the optimization model, 11 mini-bus lines within different locations in Shanghai are surveyed, and the regression analysis between average mini-bus stop spacing and daily passenger flow is carried out. The regression analysis result shows that the optimal stop spacing should be controlled within $400 \mathrm{~m}$, as shown in Fig. 5. Therefore, the average stop spacing $(330 \mathrm{~m})$ calculated by proposed optimization model suggests that the model should deal with the mini-bus stop spacing problem well.

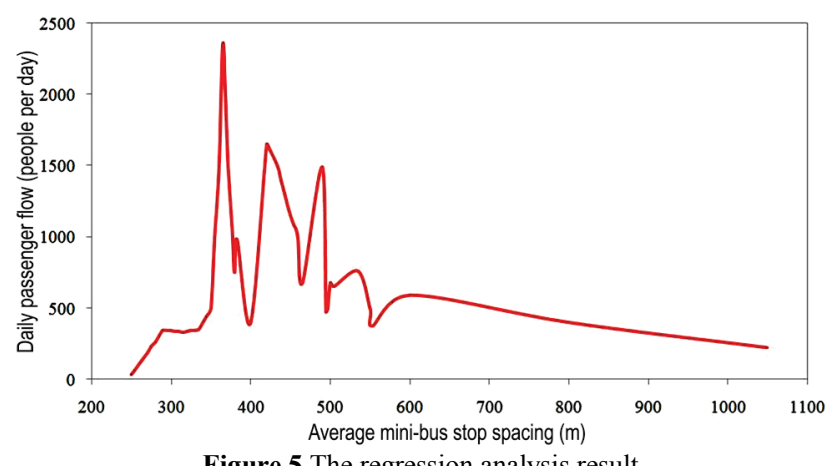

Figure 5 The regression analysis result

\subsection{Optimization of mini-bus stops}

In the case, the average mini-bus stop spacing is calculated by the optimization model and tested by the regression analysis, the value of which is $330 \mathrm{~m}$. The initial layout scheme is obtained by setting a mini-bus stop every $330 \mathrm{~m}$. Then, based on the proposed modified 
methods, the initial layout scheme is modified. Finally, mini-bus stops are determined as shown in Fig. 6.

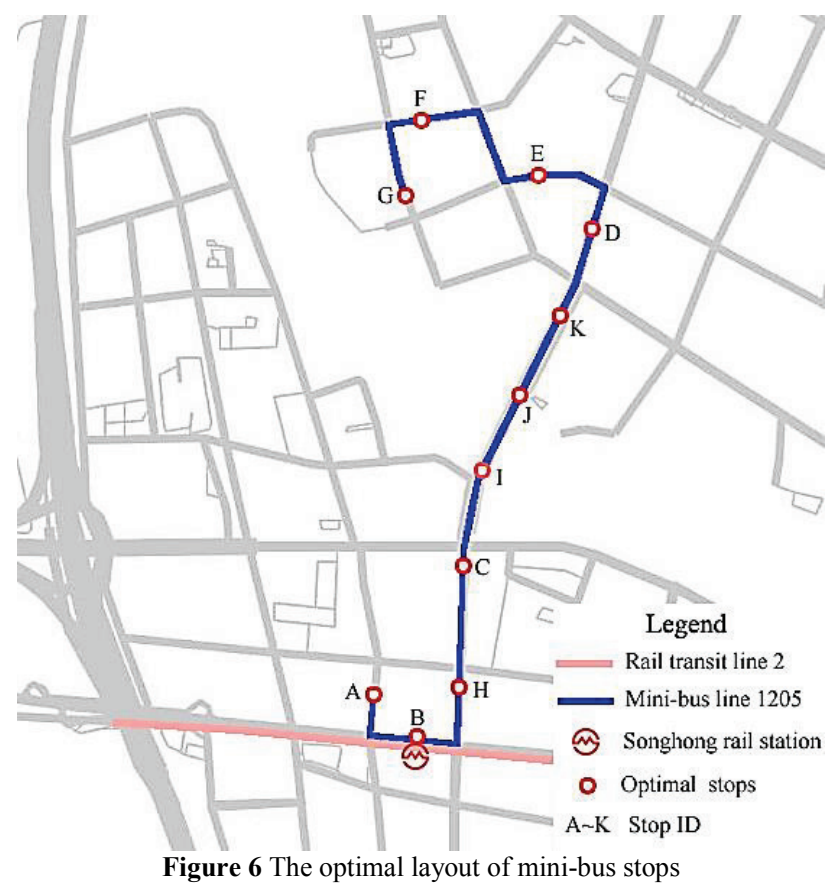

\section{Conclusion}

This paper considered the model of simple and practical locating of mini-bus stops. Therefore, this paper firstly proposed a mathematical model for mini-bus stop spacing based on Voronoi Diagrams to minimize the passengers' total travel time. In the optimization model, the Cartesian coordinate system was defined to calculate the travel time from origins or destinations to mini-bus stops. Regarding the model was a non-linear and constrained programming problem, the modified WilsonHan-Powell Sequential Quadratic Programming (SQP) technique with properties of global convergence and stability was used to solve this problem. However, the optimal mini-bus spacing calculated by the model was relatively ideal. Then, modified methods for mini-bus stop spacing were put forward, which made the optimal mini-bus spacing to be more applicable for actual situation.

To verify the validity and usefulness of proposed methods, a mini-bus line in Shanghai, China, is taken as a case study. The results show that there is an optimal minibus stop spacing of $330 \mathrm{~m}$, which is used to locate minibus stops with the proposed modification methods, proving simple and practical.

However, there are several limitations in the present study. First, we consider a mini-bus line as a feeder service for a rail transit station in this paper, while, with the development of urban rail transit system, a mini-bus line could be a feeder service for multiple rail transit stations. At that time, with the passengers behaviour change, the total time will also change, which needs further studies. Second, we only choose a typical mini-bus line to study the optimal spacing, while land use, development density can deeply affect the average spacing. Furthermore, for mini-bus lines in different locations, the average mini-bus stop spacing is also different. Therefore, the relationship between land use and transportation should be considered. Third, the modified methods pay too much attention to qualitative analysis, while quantitative analysis is insufficient. Future studies are recommended to improve the deficiencies above.

\section{Acknowledgement}

There is no conflict of interests regarding the publication of this paper. The authors are grateful to editors and the anonymous reviewers for raising constructive comments and suggestions on this paper.

\section{Reference}

[1] Sutton, J.; Gillingwater, D. Community Transport: Policy, Planning, Practice. Gordon and Breach Press, Amsterdam, Netherlands, 1995.

[2] Zhu, Z. J.; Guo, X. C.; Jun, Z.; Zhang, S. R. Route Design Model of Feeder Bus Service for Urban Rail Transit Stations. // Mathematical Problems in Engineering, Volume 2017, (2017), Article ID 1090457, 6 pages. DOI: 10.1155/2017/1090457

[3] Alterkawi, M. M. A Computer Simulation Analysis for Optimizing Bus Stops Spacing: The Case of Riyadh, Saudi Arabia. // Habitat International. 30, 3(2006), pp. 500-508. DOI: 10.1016/j.habitatint.2004.12.005

[4] Chien, S. I.; Qin, Z. Q. Optimization of Bus Stop Location for Improving Transit Accessibility. // Transportation Planning and Technology. 27, 3(2004), pp. 211-227. DOI: 10.1080/0308106042000226899

[5] Lwsley, L. Optimum Bus-stop Spacing. // Traffic Engineering and Control. 17, 11(1976), pp. 399-401.

[6] Fernandez, R. Expert System for the Preliminary Design and Location of High-capacity Bus-stops. // Traffic Engineering and Control. 34, 11(1993), pp. 533-539.

[7] Ammons, D. N. Municipal Benchmarks: Assessing Local Performance and Establishing Community Standards $\left(2^{\text {nd }}\right.$ Edition). Thousand Oaks, Sage, 2001.

[8] Reilly, J. M. Transit Service Design and Operation Practices in Western European Countries. // Transportation Research Record: Journal of the Transportation Research Board. 1604, (1997), pp. 3-8. DOI: 10.3141/1604-01

[9] Sankar, R.; Kavitha, J.; Karthi, S. Optimization of Bus Stop Locations Using GIS as A Tool for Chennai City-A Case Study. // Map India Conference/ India, 2003.

[10] El-Shair, I. M. GIS and Remote Sensing in Urban Transportation Planning: A Case Study of Birkenhead, Auckland. // Map India Conference/ India, 2003.

[11] Wirashinghe, S. C.; Ghoneim N. S. Spacing of Bus-stops for Many to Many Travel Demand. // Transportation Science. 15, 3(1981), pp. 210-221. DOI: 10.1287/trsc.15.3.210

[12] Kuah, G. K.; Perl, J. Optimization of Feeder Bus Routes and Bus-stop Spacing. // Journal of Transportation Engineering. 114, 3(1988), pp. 341-353. DOl: 10.1061/(ASCE)0733-947X(1988)114:3(341)

[13] Furth, P. G.; Rahbee, A. B. Optimal Bus Stop Spacing through Dynamic Programming and Geographic Modeling. // Transportation Research Record: Journal of the Transportation Research Board. 1731, (2000), pp. 15-22. DOI: $10.3141 / 1731-03$

[14] Saka, A. A. Model for Determining Optimum Bus-stop Spacing in Urban Areas. // Journal of Transportation Engineering. 127, 3(2001), pp. 195-199. DOI: 10.1061/(ASCE)0733-947X(2001)127:3(195)

[15] Ibeas, Á.; Dell’Olio, L.; Alonso, B.; Sainz, O. Optimizing Bus Stop Spacing in Urban Areas. // Transportation 
Research Part E: Logistics and Transportation Review. 46, 3(2010), pp. 446-458. DOI: 10.1016/j.tre.2009.11.001

[16] Delmelle, E. M.; Li, S.; Murray, A. T. Identifying Bus Stop Redundancy: A Gis-based Spatial Optimization Approach. // Computers, Environment and Urban Systems. 36, 5(2012), pp. 445-455. DOI: 10.1016/j.compenvurbsys.2012.01.002

[17] Zhao, L. H.; Chien, S. I. Investigating the Impact of Stochastic Vehicle Arrivals to Optimal Spacing and Headway for A Feeder Bus Route. // Journal of Advanced Transportation. 49, 3(2015), pp. 341-357. DOl: 10.1002/atr.1270

[18] Tica S. et al. Planning and Design of Urban Public Transport Line Network in City Belgrade (MassTransNet), Transport study, University of Belgrade - Faculty of Traffic and Transport Engineering, Belgrade, Serbia, 2015.

[19] Wright, L.; Hook, W. Bus Rapid Transit Planning Guide (3rd Edition). Institute for Transportation \& Development Policy Press, New York, 2007.

[20] Huang, J. Z.; Yu, B. A Research on Integrating Community Bus with Urban Railway System: The Case Study of Shanghai. // Journal of Urban Planning Forum. 216, 3(2014), pp. 77-84.

[21] Farwell, R. G.; Marx, E. Planning, Implementation, and Evaluation of OmniRide Demand-driven Transit Operations: Feeder and Flex-route Services.// Transportation Research Record: Journal of the Transportation Research Board. 1557, (1996), pp. 1-9. DOI: 10.3141/1557-01

[22] Schöbel, A. Locating Stops along Bus or Railway Lines: A Bicriteria Problem. // Annals of Operations Research. 136, 1(2005), pp. 211-227. DOI: 10.1007/s10479-005-2046-0

[23] Groß, D. R. P.; Hamacher, H. W.; Horn S.; Schöbel A. Stop Location Design in Public Transportation Networks: Covering and Accessibility objectives. // TOP. 17, 2(2009), pp. 335-346. DOI: 10.1007/s11750-008-0061-4

[24] Alshalalfah, B. W. Planning, Design and Scheduling of Flex-Route Transit Service.// Doctoral dissertation, University ofToronto, 2009.

[25] Quadrifoglio, L.; Dessouky, M. M. Sensitivity Analyses over the Service Area for Mobility Allowance Shuttle Transit (MAST) Services. // Computer-aided Systems in Public Transport. 600, (2008), pp. 419-432. DOI: 10.1007/978-3-540-73312-6_22

[26] Novaes, A. G. Development of A Computational System to Determine the Optimal Bus-stop Spacing in Order to Minimize the Travel Time of All Passengers. Berlin, Germany: Spring-Verlag Press, 2011.

[27] Xin, Y.; Fu, L.; Saccomanno, F. F. Assessing Transit Level of Service along Travel Corridors: Case Study Using Transit Capacity and Quality of Service Manual. // Transportation Research Record: Journal of the Transportation Research Board.1927, (2005), pp. 257-267. DOI: 10.3141/1927-29

[28] Okabe, A.; Boot, B.; Sugihara, K. Spatial Tessellations: Concepts and Applications of Voronoi Diagrams. // John Wiley \& Sons, Inc. 2000. pp. 357-363.

[29] Gill, P. E.; Murray, W.; Saunders, M. A. Snopt: An SQP Algorithm for Large-Scale Constrained Optimization. //
Siam Journal on Optimization. 12, 4(2002), pp. 979-1006. DOI: $10.1137 /$ S0036144504446096

[30] Burke, J. V. A Sequential Quadratic Programming Method for Potentially Infeasible Mathematical Programs. // Journal of Mathematical Analysis and Applications. 139, 2(1989), pp. 319-351. DOI: 10.1016/0022-247X(89)90111-X

[31] Sahba, M. Globally Convergent Algorithm for Nonlinearly Constrained Optimization Problems. // Journal of Optimization Theory \& Applications. 52, 2(1987), pp. 291309. DOI: 10.1007/BF00941288

[32] Burke, J. V.; Curtis, F. E.; Wang, H. A Sequential Quadratic Optimization Algorithm with Rapid Infeasibility Detection. // Siam Journal on Optimization. 24, 2(2014), pp. 839-872. DOI: $10.1137 / 120880045$

[33] Räsänen, M. Functionality of A Bus Stop at Exit or Merging Lanes and Its Impact on Driver Behavior. // Traffic Engineering and Control. 47, 1(2006), pp. 29-32.

\section{Authors' addresses}

\section{Zhenjun Zhu, Ph.D. Candidate}

Jiangsu Key Laboratory of Urban ITS, Southeast University Jiangsu Province Collaborative Innovation Center of Modern Traffic Technologies, Southeast University

School of Transportation, Southeast University Si Pai Lou No. 2, Nanjing 210096, China E-mail: zhuzhenjun@seu.edu.cn

\section{Xiucheng Guo, Dr. Prof.}

Corresponding author

School of Transportation, Southeast University

Si Pai Lou No. 2, Nanjing 210096, China

E-mail: seuguo@163.com

\section{Hongsheng Chen, Ph.D. Candidate}

School of Architecture, Southeast University

Si Pai Lou No. 2, Nanjing 210096, China

E-mail: hongsheng.chen2006@163.com

\section{Jun Zeng, Ph.D. Candidate}

Jiangsu Key Laboratory of Urban ITS, Southeast University Jiangsu Province Collaborative Innovation Center of Modern Traffic Technologies, Southeast University

School of Transportation, Southeast University

Si Pai Lou No. 2, Nanjing 210096, China

E-mail: zengjun@seu.edu.cn

\section{Jiangling Wu, Ph.D. Candidate}

School of Highway, Chang'an University

Middle Section of South 2 Ring Rd., Xi'an 710064, China

E-mail: wujiangling2006@gmail.com 